\title{
Analysis of the genetic architecture of energy balance and its major determinants dry matter intake and energy-corrected milk yield in primiparous Holstein cows
}

\author{
N. Krattenmacher, ${ }^{1 *} \dagger$ G. Thaller, ${ }^{1}$ and J. Tetens ${ }^{2,3 *}$ \\ ${ }^{1}$ Institute of Animal Breeding and Husbandry, Christian-Albrechts-University, D-24118 Kiel, Germany \\ ${ }^{2}$ Department of Animal Sciences, Functional Breeding Group, Georg-August-University Göttingen, D-37077 Göttingen, Germany \\ ${ }^{3}$ Center for Integrated Breeding Research, Georg-August-University Göttingen, D-37077 Göttingen, Germany
}

\section{ABSTRACT}

The focus of modern dairy cow breeding programs has shifted from being mainly yield based toward balanced goals that increasingly consider functional traits such as fertility, metabolic stability, and longevity. To improve these traits, a less pronounced energy deficit postpartum is considered a key challenge. On the other hand, feed efficiency and methane emissions are gaining importance, possibly leading to conflicts in the design of breeding goals. Dry matter intake (DMI) is one of the major determinants of energy balance (EB), and recently some efforts were undertaken to include DMI in genomic breeding programs. However, there is not yet a consensus on how this should be achieved as there are different goals in the course of lactation (i.e., reducing energy deficit postpartum vs. subsequently improving feed efficiency). Thus, the aim of this study was to gain more insight into the genetic architecture of energy metabolism across lactation by genetically dissecting EB and its major determinants DMI and energy-corrected milk (ECM) yield at different lactation stages applying random regression methodology and univariate and multivariate genomic analyses to data from 1,174 primiparous Holstein cows. Daily heritability estimates ranged from 0.29 to $0.49,0.26$ to 0.37 , and 0.58 to 0.68 for EB, DMI, and ECM, respectively, across the first $180 \mathrm{~d}$ in milk (DIM). Genetic correlations between ECM and DMI were positive, ranging from 0.09 (DIM 11) to 0.36 (DIM 180). However, ECM and EB were negatively correlated $\left(\mathrm{r}_{\mathrm{g}}=-0.26\right.$ to -0.59$)$. The strongest relationship was found at the onset of lactation, indicating that selection for increased milk yield at this stage will result in a more severe energy deficit postpartum. The results also indicate that EB is more affected by DMI $\left(\mathrm{r}_{\mathrm{g}}=0.71\right.$ to 0.81$)$ than by its other major

Received July 31, 2018.

Accepted December 13, 2018.

*These authors contributed equally to this work.

†Corresponding author: nbuttchereit@tierzucht.uni-kiel.de determinant, ECM. Thus, breeding for a higher DMI in early lactation seems to be a promising strategy to improve the energy status of dairy cows. We found evidence that genetic regulation of energy homeostasis is complex, with trait- and lactation stage-specific quantitative trait loci suggesting that the trajectories of the analyzed traits can be optimized as mentioned above. Especially from the multivariate genomic analyses, we were able to draw some conclusions on the mechanisms involved and identified the genes encoding fumarate hydratase and adiponectin as highly promising candidates for EB, which will be further analyzed.

Key words: energy balance, dry matter intake, energycorrected milk yield, genetics, genomics

\section{INTRODUCTION}

In the recent past, dairy cattle breeding programs have broadened and adapted to cover functional traits. However, selection is still mainly for high milk yield, resulting in a partial shift of available energy toward milk production at the cost of other energy-consuming processes, especially those that are scarcely considered in breeding goals (e.g., reaction to pathogens; Rauw et al., 1998). This is worsened by the fact that energy expenditure is higher than energy intake in early lactation (Bauman and Currie, 1980). Therefore, exclusive breeding for high milk yield will intensify the energy deficit postpartum. This, in turn, leads to undesirable side effects for immunological and reproduction traits and consequently for animal welfare (Rauw et al., 1998).

Genomic selection has the power to increase production levels even faster than in the past, which may result in more dramatic consequences for functional traits that are not under selection. For the dairy research herd Karkendamm, the severity and duration of the energy deficit postpartum has increased remarkably over a relatively short period of time (von Leesen et al., 2014), and we hypothesize that this is at least partly due to the increased intensity and accuracy of selection for milk production. However, genomic information can 
also be used to decrease the energy deficit in early lactation, thereby improving health and fertility.

Genomic selection for DMI, which is the major determinant of energy balance (EB; Hüttmann et al., 2009), is challenging because the trait is difficult and costly to measure; therefore, the reference population is small even though international collaboration has been established to increase its size. However, using the data set of the global Dry Matter Initiative, which represents the largest existing international database consisting of individual dairy animal DMI records from Europe, North America, and Australasia (Berry et al., 2014) and their associated genotypes (Pryce et al., 2014), de Haas et al. (2015) demonstrated that genomic prediction of DMI is possible with a mean prediction accuracy of 0.44. Although accuracy of genomic selection for DMI is less good than that for production traits, this can be considered as great progress because we were unable to include this trait in breeding goals until we entered the genomics era.

In the study of de Haas et al. (2015), predicted DMI at DIM 70 was used as the phenotype because this was the point of time when the largest number of actual DMI observations existed within the complete data set (see also Berry et al., 2014). For future data collection, we need to determine the optimal phenotype and a strategy for data recording. Continuous recording of DMI throughout the whole lactation is expensive and not absolutely necessary; however, DMI should be measured at more than one lactation stage for 2 reasons: (1) Tetens et al. (2014) found out that genetic regulation of DMI differs between early and mid lactation, and (2) selection for DMI has to be seen in the context of conflicting requirements regarding short-term efficiency, which can be improved by an appropriate reallocation of energy, and long-term efficiency, which requires changes of acquisition (Puillet et al., 2016). In early lactation, DMI should be increased to breed for well-conditioned animals with less severe energy deficits and, consequently, fewer physiological and immunological problems, which are a limiting factor for longevity and the profitability of milk production. During mid and late lactation, cows should consume less feed or, in other words, a reasonable amount of feed that matches their milk production. Feed represents a major proportion of the variable costs in dairy production; therefore, an optimization of the overall feed efficiency is crucial with regard to economic efficiency.

For the inclusion of DMI in breeding goals, we need better insights into the genetic architecture of EB, DMI, and milk yield. On the one hand, exact knowledge on heritability estimates and genetic correlations in different lactation stages might be the key to a successful redefinition of breeding programs. On the other hand, knowledge of genes influencing 1, 2, or all 3 of these traits simultaneously may provide deeper insights into the underlying regulatory circuits. The aim of the current study was therefore to examine the degree and change in heritability of $\mathrm{EB}$ and its major determinants (DMI and ECM yield) across lactation and to estimate genetic correlations among EB, DMI, and ECM using random regression. Furthermore, deregressed EBV for all 3 traits were estimated and the results for DIM 11 and for every fifth lactation day ranging from DIM 15 to 180 were used as phenotypes for univariate and multivariate genome-wide association studies (GWAS) with the aim of identifying genomic regions with a significant effect on EB, DMI, or ECM at specific or multiple stages of lactation. By using this approach to investigate genetic relationships between the aforementioned traits, it is possible to identify possible pleiotropic effects on different energy-related traits, deduce mechanistic hypotheses and candidate genes, and determine whether remodeling of the lactation curve trajectory of DMI is a possible strategy to improve both energy status and production efficiency.

\section{MATERIALS AND METHODS}

\section{Animals and Phenotypes}

Data from 1,174 primiparous Holstein Friesian cows descending from 286 sires and including 191 daughterdam pairs were recorded between September 2005 and December 2012 on the dairy research farm Karkendamm (Institute of Animal Breeding and Husbandry, Christian-Albrechts-University, Kiel, Germany). This farm ran a bull dam performance test when data were recorded, and all bull dam candidates had to complete a test period under commercial conditions in a freestall barn until DIM 180. Nonqualified primiparous cows left the herd afterward. Thus, only records between DIM 11 (start of feed intake recording) and DIM 180 were used in the present investigation.

Cows were milked twice per day, and milk yield was automatically recorded at every milking. Milk composition was analyzed weekly based on samples collected from 2 consecutive milkings. Energy-corrected milk was calculated according to Kirchgeßner (1997):

$$
\begin{aligned}
& \text { ECM }(\mathrm{kg})=\text { milk yield }(\mathrm{kg}) \\
& \times \frac{(0.39 \times \text { fat } \%+0.24 \times \text { protein } \%+0.17 \times \text { lactose } \%)}{3.17} .
\end{aligned}
$$

For this purpose, milk composition per day was obtained by weighting the respective or previous analysis values per day with the respective milk yield. 


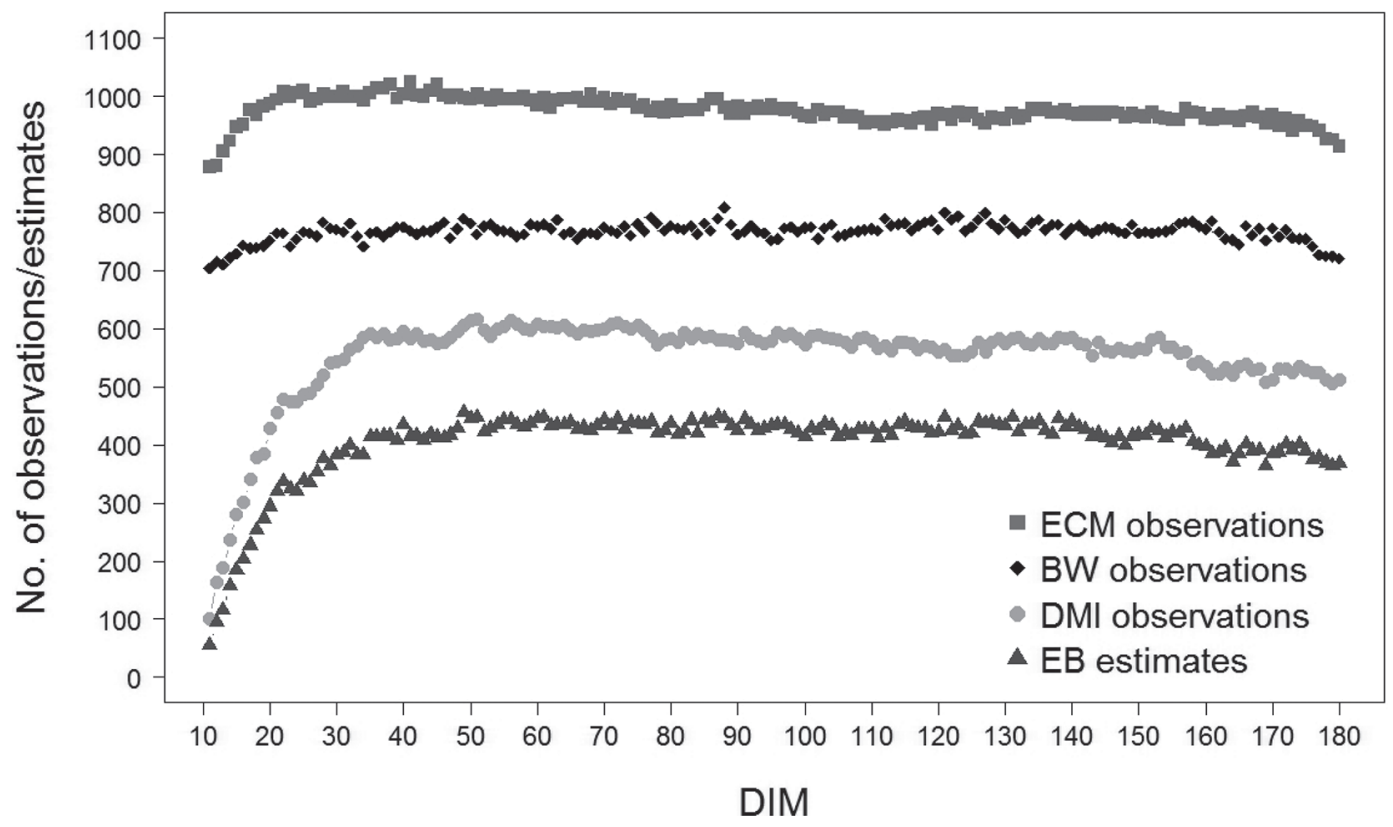

Figure 1. Data distribution across DIM 11 to 180 for ECM, BW, DMI, and energy balance (EB).

Cows were weighed after every milking since March 2006. Morning and evening BW were averaged to derive a daily value.

Animals were fed a TMR diet ad libitum. Daily TMR intake was recorded for each animal via single feeding troughs equipped with a weighing unit and automatic cow identification. Because cows were generally housed separately during the first 10 DIM, no feed intake data were available for this period. Individual TMR intake was deleted for the first and last day with TMR intake information and when cows were separated for insemination or pregnancy testing. Values obtained for fresh TMR intake were discarded if they were among the 0.5 percentage highest or 0.5 percentage lowest values, resulting in a range of fresh TMR intake between 4.8 and $77.3 \mathrm{~kg}$. Dry matter content of the TMR was analyzed twice weekly. The average lactation net energy of TMR was $7.1 \mathrm{MJ} / \mathrm{kg}$ of DM. Fixed amounts of concentrates were dispensed via concentrate feeders. Energy balance was calculated as the difference between energy intake and energy requirements for milk production and maintenance based on feed intake, milk yield and constituents, and the daily weights as described by Buttchereit et al. (2010).

Records for a specific trait were excluded from the analyses if the number of observations per cow for this trait across the entire period was less than 4 . This resulted in 824 primiparous cows with EB data, 910 cows with DMI records, and 1,174 cows with ECM records. Figure 1 shows the data distribution across DIM 11 to 180 for ECM, BW, DMI, and EB. The number of ob- servations per DIM was lowest in early lactation for all analyzed traits. From the third week of lactation (ECM and $\mathrm{BW}$ ) and fourth week of lactation (DMI and EB) on, data were relatively evenly distributed. A summary of the data is given in Table 1. In addition, Figure 2a to $\mathrm{d}$ shows the trend of the mean for ECM, BW, DMI, and EB across DIM 11 to 180 and the standard deviations for the traits throughout DIM 11 to 180 . The average EB was negative until DIM 55 and stabilized between DIM 55 and 63 (switching from positive to negative and vice versa during this period). It should be noted, however, that the duration of the energy deficit varied largely across cows and that some cows did not change into a state of positive EB throughout the entire observation period (see also von Leesen et al., 2014).

\section{Statistical Analysis}

A pedigree file was created by tracing the pedigree of cows with data 3 generations back. The resulting file consisted of 5,683 animals. Data were analyzed using a random regression animal model considering the fixed effects of test day, age at first calving, and stage of lactation. Age at first calving was divided into 5 classes (21-25, 26, 27, 28, and 29-38 mo). The general lactation curve was modeled by the function according to Ali and Schaeffer (1987). The random regression coefficients for permanent and additive genetic effects were modeled applying Legendre polynomials of 2 degrees. For EB and DMI, second-degree polynomials worked best, and we decided to choose the same model for all 
Table 1. Descriptive statistics for energy balance (EB), DMI, ECM, fat content, protein content, lactose content, and BW (first lactation, DIM 11-180)

\begin{tabular}{lrrrrr}
\hline Trait & \multicolumn{1}{c}{$\mathrm{n}$} & \multicolumn{1}{c}{ Mean } & \multicolumn{1}{c}{$\mathrm{SD}$} & Minimum & Maximum \\
\hline EB $(\mathrm{MJ}$ of NE $/ \mathrm{d})$ & 68,436 & 5.16 & 35.86 & -141.80 & 185.59 \\
DMI $(\mathrm{kg} / \mathrm{d})$ & 93,797 & 20.17 & 4.83 & 1.99 & 45.45 \\
ECM $(\mathrm{kg} / \mathrm{d})$ & 165,805 & 32.72 & 4.69 & 2.50 & 53.64 \\
Fat $(\%)$ & 24,138 & 3.64 & 0.59 & 1.22 & 8.68 \\
Protein $(\%)$ & 24,138 & 3.24 & 0.24 & 1.96 & 6.01 \\
Lactose $(\%)$ & 24,237 & 4.88 & 0.15 & 3.17 & 5.38 \\
BW $(\mathrm{kg})$ & 130,452 & 600.03 & 54.48 & 404.00 & 847.00 \\
\hline
\end{tabular}

3 traits. Using higher orders would have led to convergence problems. The resulting model was

$\mathrm{y}_{\mathrm{ijklm}}=\mathrm{TD}_{\mathrm{i}}+\mathrm{AFC}_{\mathrm{j}}+\sum_{n=1}^{4} \mathrm{~b}_{\mathrm{n}} \mathrm{x}_{\mathrm{ijklmn}}(\mathrm{d})+\sum_{n=0}^{2} \mathrm{p}_{\mathrm{kn}} \mathrm{z}_{\mathrm{ijklmn}}(\mathrm{d})$

$+\sum_{n=0}^{2} \mathrm{a}_{\ln } \mathrm{z}_{\mathrm{ijklmn}}(\mathrm{d})+\mathrm{e}_{\mathrm{ijklm}}$,

where $y_{\mathrm{ijklm}}=$ the mth observation of EB, DMI, or $\mathrm{ECM} ; \mathrm{TD}_{\mathrm{i}}=$ fixed effect of test day i $(\mathrm{i}=1-1,714$ for $\mathrm{EB}, \mathrm{i}=1-2,023$ for DMI, and $\mathrm{i}=1-2,649$ for $\mathrm{ECM})$; $\mathrm{AFC}_{\mathrm{j}}=$ fixed effect of age at first calving $(\mathrm{j}=1-5) ; \mathrm{b}_{\mathrm{n}}$ $=$ fixed regression coefficients on lactation day $\mathrm{d}$, with $\mathrm{x}_{\mathrm{ijk} l \mathrm{~m} 1}(\mathrm{~d})=\mathrm{d} / 190, \mathrm{x}_{\mathrm{ijklm} 2}(\mathrm{~d})=(\mathrm{d} / 190)^{2}, \mathrm{x}_{\mathrm{ijklm} 3}(\mathrm{~d})=$ $\ln (190 / \mathrm{d})$, and $\mathrm{x}_{\mathrm{ijklm} 4}(\mathrm{~d})=[\ln (190 / \mathrm{d})]^{2} ; \mathrm{p}_{\mathrm{kn}}=$ random regression coefficients for the permanent environmental effect of the kth animal with phenotypic records; $\mathrm{a}_{\mathrm{ln}}=$ random regression coefficients for the additive genetic effect of animal 1 in the pedigree, with $z_{\mathrm{ijklm} 0}(\mathrm{~d})=1$, $\mathrm{z}_{\mathrm{ijk} \operatorname{lm} 1}(\mathrm{~d})=-1+2\left(\mathrm{~d}-11 / \mathrm{d}_{\max }-11\right)$, and $\mathrm{z}_{\mathrm{ijklm} 2}(\mathrm{~d})=$ $0.5\left\{3\left[-1+2\left(\mathrm{~d}-11 / \mathrm{d}_{\max }-11\right)\right]^{2}-1\right\}(\mathrm{k}=1-824$ for $\mathrm{EB}, \mathrm{k}=1-910$ for DMI, and $\mathrm{k}=1-1,174$ for ECM; $1=$ $1-5,683)$; and $\mathrm{e}_{\mathrm{ijklm}}=$ random error.

Residual errors were expected to have heterogeneous variances, so the first 180 DIM were split into 6 measurement error classes (11-30, 31-60, 61-90, 91-120, 121-150, and 151-180 DIM). Within these classes, residual errors were assumed to be homogeneous. Residual covariances were assumed to be zero.

Variance components were estimated univariately and bivariately by REML using the software package ASReml 3.0 (Gilmour et al., 2009). Approximate standard errors for daily heritability and daily repeatability estimates and genetic correlations across lactation were calculated with the method proposed by Fischer et al. (2004). ASReml 3.0 was also used for the estimation of EBV for EB, DMI, and ECM.

\section{Genomic Analyses}

A total of 876 animals with phenotypic information were genotyped using the Illumina SNP50v1 BeadChip comprising a total of 54,001 SNP markers. The amount of missing genotypes per individual was $<1 \%$ on average, and no animal had to be removed due to poor genotyping quality. Loci with $>10 \%$ missing genotypes, a minor allele frequency $<0.025$, or unknown genomic position based on the bovine genome assembly UMD 3.1 (https://oct2018.archive.ensembl.org/Bos_taurus/ Info/Annotation) were excluded, resulting in a final set of 40,583 informative markers. Quality control and data preparation were done with the plink package (Purcell et al., 2007).

Genome-wide association studies were carried out as described by Tetens et al. (2014) applying a linear mixed model approach using the freely available software tool GEMMA (genome-wide efficient mixed model association; Zhou and Stephens, 2012), with the daily EBV for DIM 11 and for every fifth day ranging from DIM 15 to 180 as phenotypes. These EBV were deregressed by dividing them by their respective reliability. For each marker, GEMMA fits the following mixed model:

$$
\mathbf{y}=\mathbf{W} \boldsymbol{\alpha}+\mathbf{X} \beta+\mathbf{u}+\varepsilon,
$$

where $\mathbf{y}$ is an $n \times 1$ vector of deregressed EBV for $n$ cows; $\mathbf{W}$ is an $\mathrm{n} \times \mathrm{c}$ incidence matrix of covariates, where $\mathrm{c}$ is the number of covariates; $\boldsymbol{\alpha}$ is a vector of corresponding coefficients including the intercept; $\mathbf{X}$ is an $n \times 1$ vector of marker genotypes at the locus tested and $\beta$ is the corresponding effect size; and $\mathbf{u}$ is a vector of random genetic effects, with $\mathbf{u} \sim N\left(0, \mathbf{A} \sigma_{\mathrm{g}}^{2}\right)$, where $\sigma_{\mathrm{g}}^{2}$ represents the genetic variance and $\mathbf{A}$ is the relationship matrix. Here, the genomic relationship matrix was calculated with the freely available GCTA (genomewide complex trait analysis) software tool according to Yang et al. (2011). Finally, $\varepsilon$ is a random residual term, with $\varepsilon \sim N\left(0, \mathbf{I} \sigma_{\varepsilon}^{2}\right)$, where $\sigma_{\varepsilon}^{2}$ represents the residual variance and $\mathbf{I}$ represents an identity matrix. The alternative hypothesis of $\mathrm{H} 1(\beta \neq 0)$ was tested against the null hypothesis $\mathrm{H0}(\beta=0)$ using the Wald test.

Besides the univariate analyses, bi- and multivariate analyses as also implemented in GEMMA (Zhou 
and Stephens, 2014) were conducted using the same deregressed EBV as in the univariate analyses. Both uni- and bivariate GWAS models were also fitted without including the marker effect to be tested (termed null models later) to estimate the variance explained by all markers (chip heritability) and the genomic correlations between traits for the same DIM, respectively.

To account for multiple testing, the modified Bonferroni approach (simpleM) of Gao et al. (2008) was applied, which accounts for the fact that association tests in genome-wide studies are not independent due to linkage disequilibrium between markers. Based on a pairwise marker correlation matrix, the number of effective tests to be used in a subsequent Bonferroni correction is estimated, which is less computationally demanding compared with permutation procedures (Gao et al., 2010).

a)

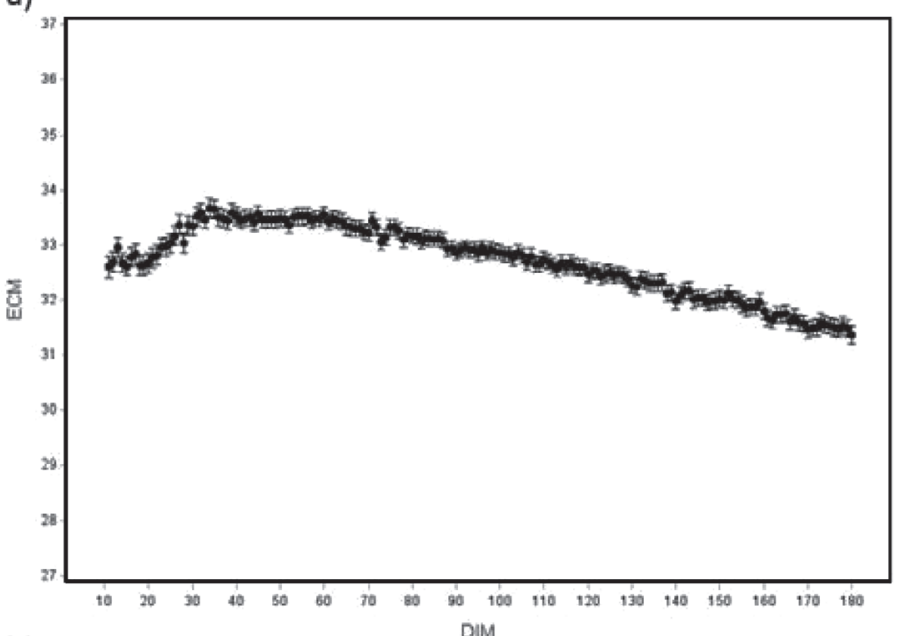

b)

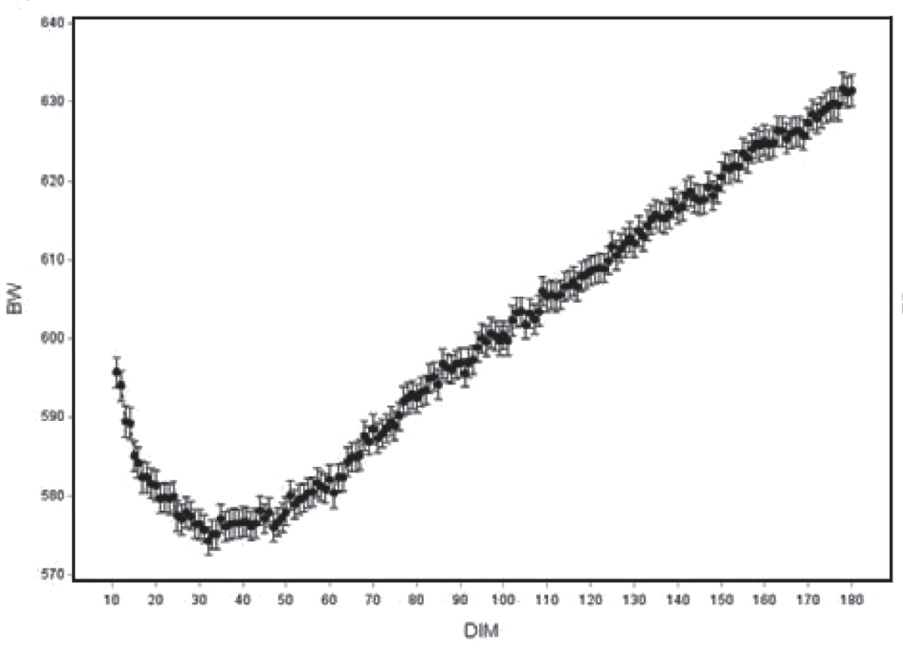

\section{RESULTS AND DISCUSSION}

\section{Daily Repeatability and (Chip) Heritability Estimates for $E B, D M I$, and ECM}

Figure 3 shows repeatability and heritability estimates for EB, DMI, and ECM across the first 180 DIM. The highest repeatability was found for ECM. Repeatability estimates remained above 0.78 for this trait across all analyzed DIM. Repeatability estimates for $\mathrm{EB}$ showed more variation, ranging from 0.42 to 0.65 , with the highest values found at the beginning of lactation. Repeatability estimates of DMI were also moderate and ranged from 0.41 to 0.56 .

For each single DIM (11-180), the highest heritability was found for ECM $\left(\mathrm{h}^{2}=0.58-0.68\right)$ and the lowest heritability was found for DMI $\left(\mathrm{h}^{2}=0.26-0.37\right)$.

c)

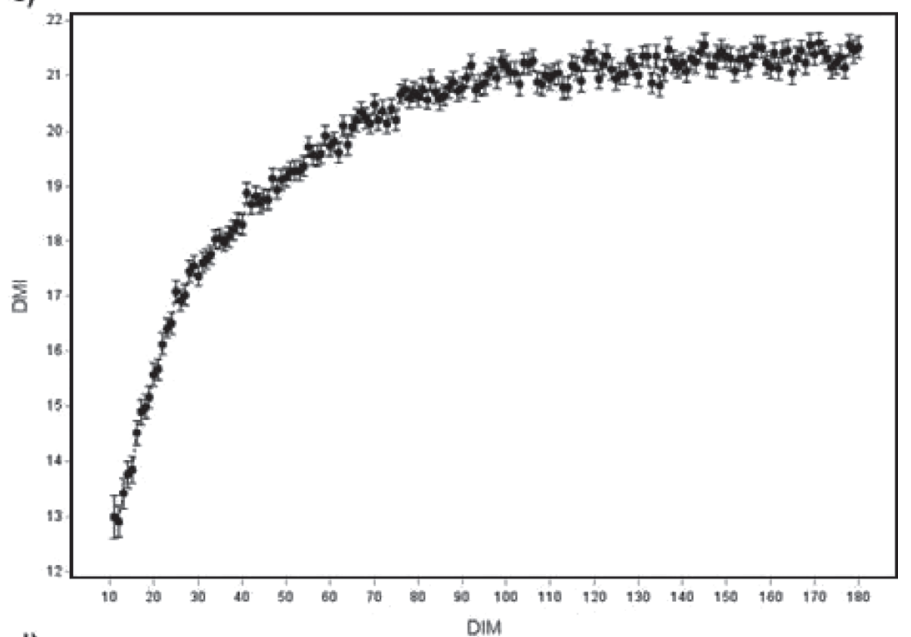

d)

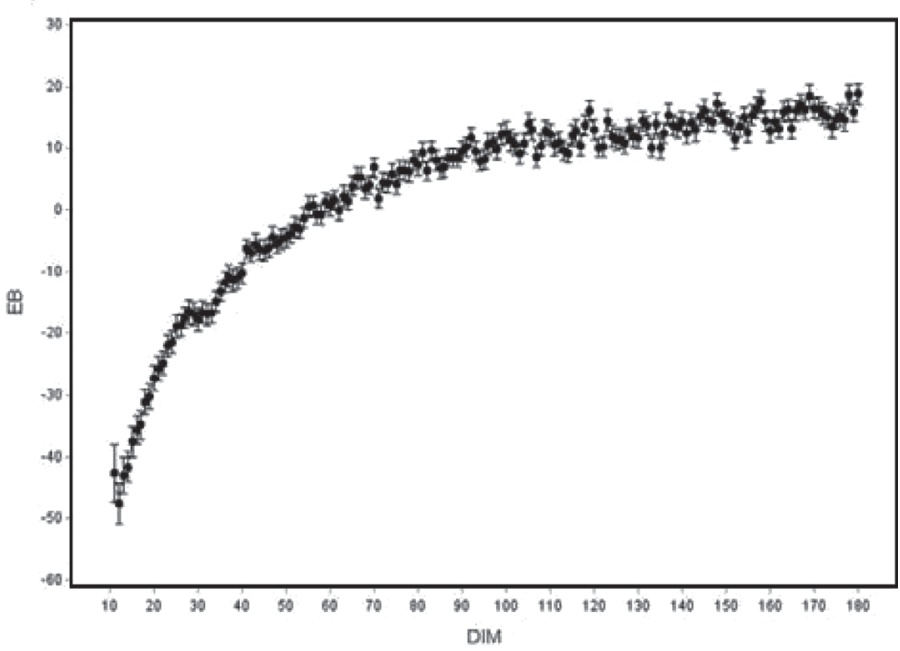

Figure 2. Trend of the mean and SD across DIM 11 to 180 for (a) ECM (in kg), (b) BW (in kg), (c) DMI (in kg), and (d) energy balance $\left(\mathrm{EB}\right.$; in $\mathrm{MJ}$ of $\mathrm{NE}_{\mathrm{L}}$ ). 


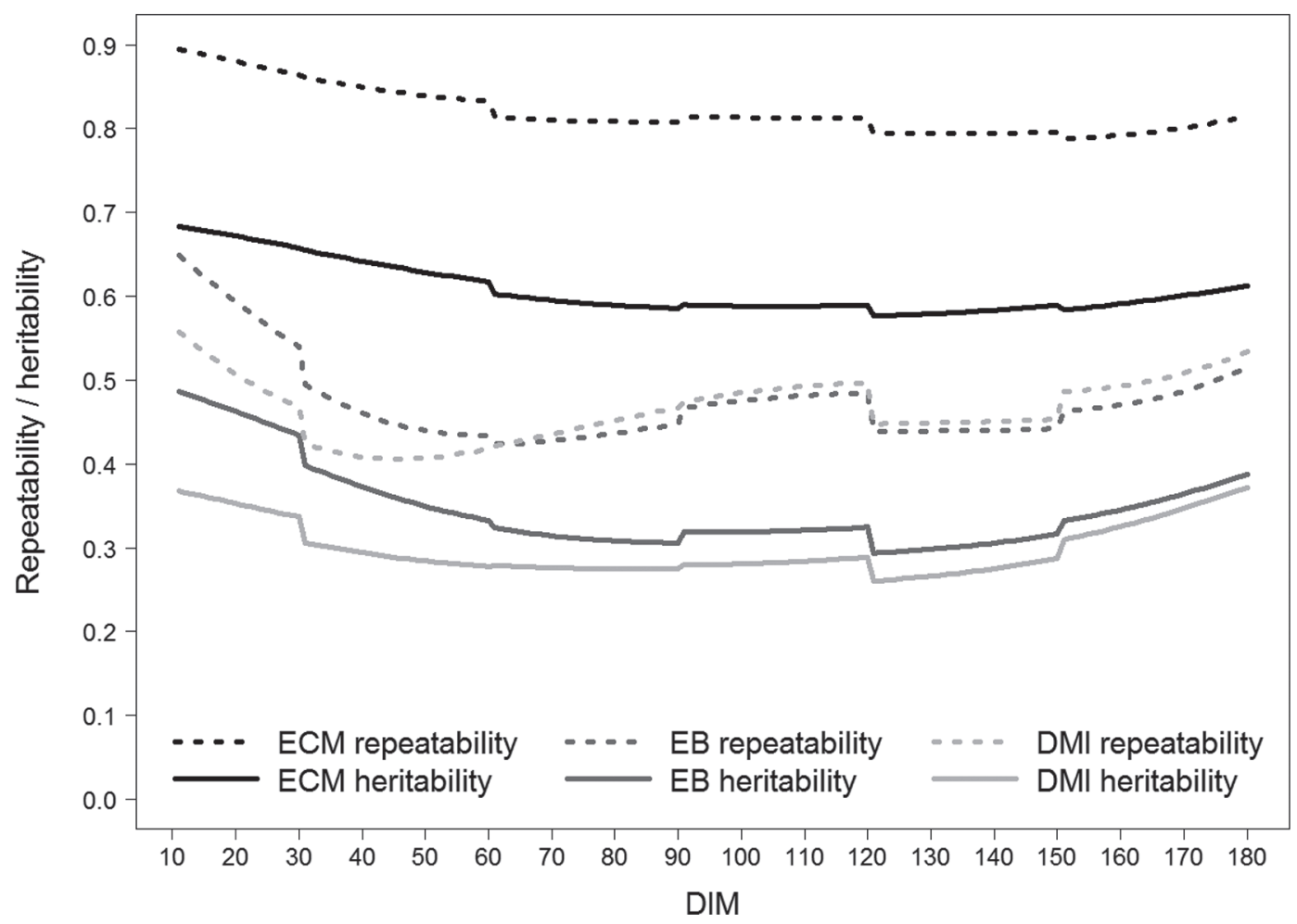

Figure 3. Heritability and repeatability estimates for energy balance (EB), DMI, and ECM across the first 180 DIM. Lines represent daily estimates obtained from random regression analyses. Approximate SE of heritability estimates ranged from 0.03 to 0.05 , 0.02 to 0.04 , and 0.04 to 0.04 for EB, DMI, and ECM, respectively. Approximate SE of repeatability estimates ranged from 0.01 to $0.02,0.01$ to 0.02 , and 0.00 to 0.01 for EB, DMI, and ECM, respectively.

The heritability estimates of EB ranged between 0.29 and 0.49 and showed a similar pattern (i.e., a slightly parabolic curve as the heritability for DMI; Figure 3). The heritability of EB is intermediate between the heritabilities of the other traits throughout the entire interval, which can be expected as DMI and ECM are the key determinants of EB.

As discussed earlier (Tetens et al., 2014), the mean heritability for DMI across the first 180 DIM was in general agreement with other studies, although some authors (Berry et al., 2007; Spurlock et al., 2012) found different trajectories. In a more recent study, however, Li et al. (2016), who also analyzed DMI in primiparous Holstein cows across the first 180 DIM, reported a very similar trajectory, also with a similar mean heritability of approximately 0.3 . For EB, the overall dimension of heritability estimates is also in general agreement with previous studies, although the variation of estimates reported in the available literature is rather high. The heritabilities estimated for ECM in the current study seem high, with some values close to 0.7 . This is likely attributable to the study being conducted in a single well-managed research herd. This has also been found by Byskov et al. (2017), who compared a research herd with commercial farms. For ECM in the research herd, they found similar heritabilities as in the current study, whereas the estimates were much lower for commercial farms.

The estimates of the chip heritabilities showed a slightly different trajectory across the 180 DIM (see Supplemental Figure S1, https://doi.org/10.3168/ jds.2018-15480). For ECM, chip heritability averaged 0.49 , with the highest value of 0.5 at DIM 11 and a slight decrease toward mid lactation. The mean chip heritability values for EB and DMI were 0.41 and 0.37 , respectively, with a local minimum around DIM 40. The heritability estimates for EB and DMI obtained from the random regression models approached each other toward DIM 180, whereas the chip heritabilities diverged. However, both estimates show that the heritability changed across lactation.

\section{Genetic Correlations Within Traits Across DIM 11 to 180}

All traits under consideration are influenced by various biological processes, and there is some evidence that the major determinants of EB have a different 
genetic background across lactation stages (Strucken et al., 2015). Therefore, genetic correlations of EB, DMI, and ECM were estimated between different lactation days (DIM 11 and every 10th day from DIM 20 to 180). Genetic correlations between EB estimates from different lactation stages were all positive but inversely related to the length of the interval between compared DIM, decreasing from 1.00 to 0.37 (Figure 4a). The same is true for DMI; however, genetic correlations between DMI in early and mid lactation decreased more rapidly, reaching a minimum of 0.32 (Figure 4b). For ECM, genetic correlations remained above 0.59 (Figure 4c), suggesting that the genetics of ECM are less variable during lactation than those of DMI and EB. The approximate standard errors of the genetic correlations within a trait were generally low, ranging from 0.00 to 0.07 for EB, 0.00 to 0.08 for DMI, and 0.00 to 0.04 for ECM.

Our analyses are limited to the first 180 DIM, and thus no conclusions can be drawn regarding the correlations between early or mid and late lactation. The lower genetic correlations between lactation stages, however, indicate that selection aiming to change the trajectory of EB should focus on feed intake rather than on milk yield because there will be different directions of selection in early and mid or late lactation. However, inclusion of DMI in the breeding goal would then require repeated measurements of feed intake (Liinamo et al., 2012) or the availability of suitable proxies (e.g., derived from mid-infrared spectra routinely available from milk analysis; Shetty et al., 2017; Wallén et al., 2018).

\section{Genetic and Genomic Correlations Between Traits at the Same DIM}

Genetic correlations between ECM and DMI were all positive, ranging from 0.09 to 0.36 , with the lowest values found at DIM 11 and the highest values found at DIM 180. As expected, ECM and EB were negatively correlated across the whole observation period (i.e., early and mid lactation; $\mathrm{r}_{\mathrm{g}}=-0.26$ to -0.59$)$. The strongest relationship was found at the beginning of lactation, indicating that selection for increased milk yield in this stage will dramatically intensify the energy deficit postpartum. To address this risk, breeding for a higher DMI in the initial lactation can represent a suitable strategy because the relationship between DMI and EB was more pronounced $\left(\mathrm{r}_{\mathrm{g}}=0.71-0.81\right)$ compared with the correlation between ECM and EB. There is only a weak correlation between DMI and ECM at the beginning of lactation, which increases to 0.36 in mid lactation. This is in contrast with other studies (Manzanilla Pech et al., 2014; Li et al., 2018) a)

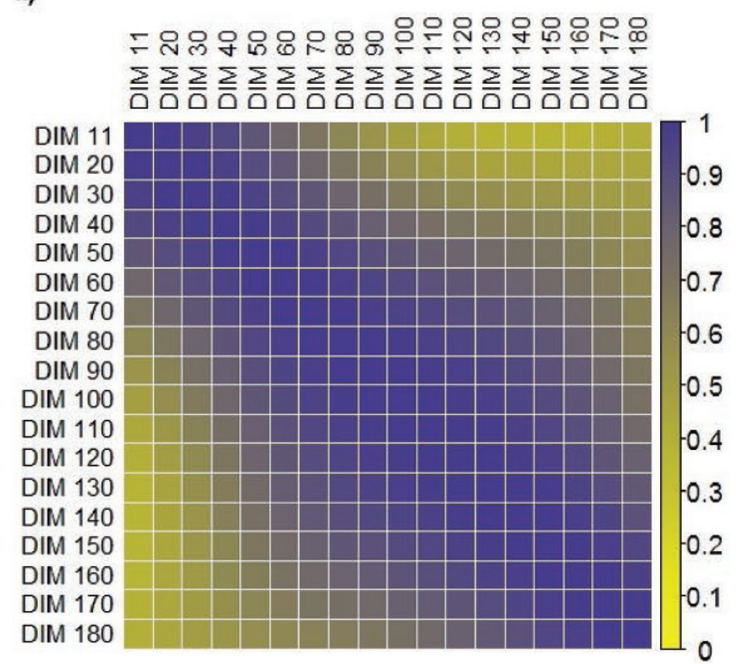

b)

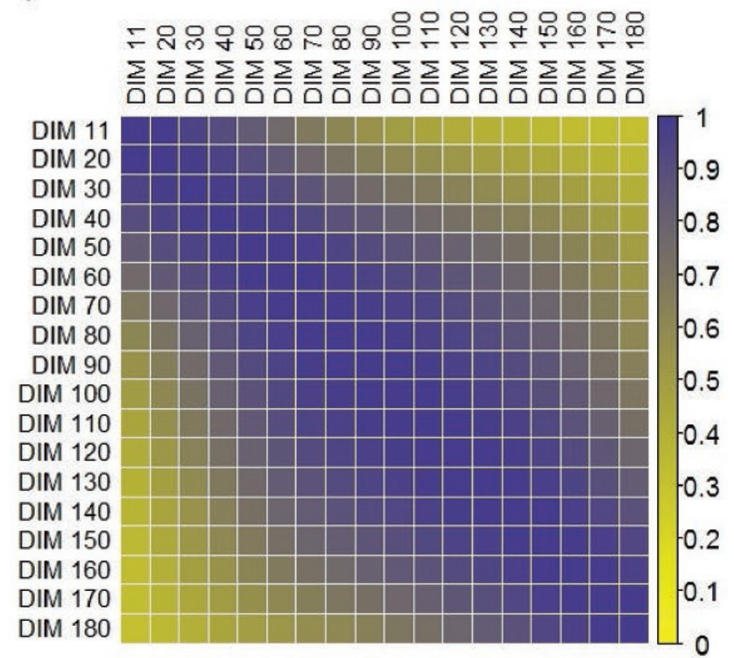

c)

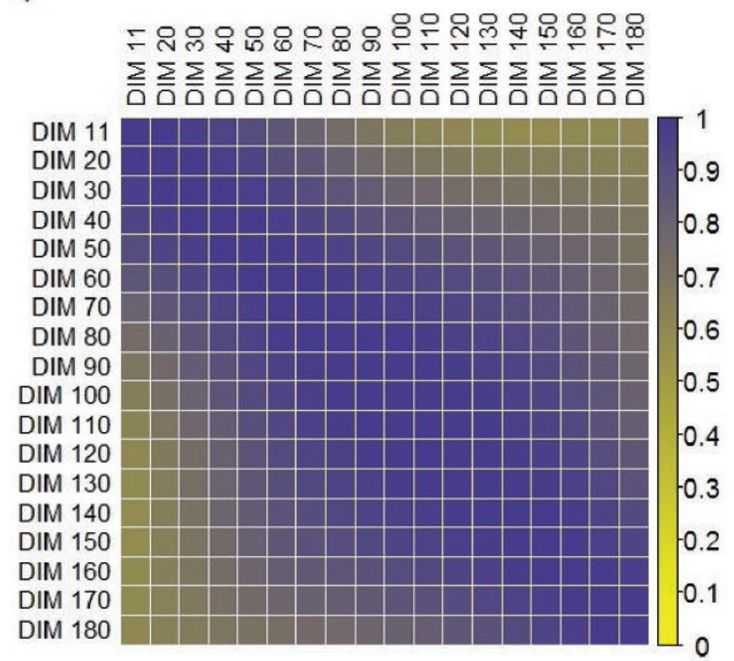

Figure 4. Genetic correlations across DIM for (a) energy balance (SE ranged from 0.00 to 0.07 ), (b) DMI (SE ranged from 0.00 to 0.08 ), and (c) ECM (SE ranged from 0.00 to 0.04 ). 
reporting much higher correlations in mid lactation. Overall, the results indicate that selection for milk yield might lead to a correlated selection response in feed intake in later lactation, whereas no such effect can be expected in early lactation, when this would be very desirable. On the other hand, it might lead to an unwantedly high increase in feed intake in late lactation. The latter can, however, not be evaluated from our data because the data are limited to the first 180 DIM. Negative genetic correlations between feed intake and milk yield as reported by other authors (Veerkamp and Thompson, 1999; Karacaören et al., 2006; Manzanilla Pech et al., 2014) were not found in the current study. The estimates of genomic correlations obtained from the polygenic effect in the null model for the bivariate GWAS were, as expected, in almost perfect concordance with the $r_{g}$ estimates from the random regression models (see Figure 5 and Supplemental Figure S2, https:// doi.org/10.3168/jds.2018-15480).

\section{Genome-Wide Association Analyses}

The results of the genome-wide association analyses are presented in Figures 6 and 7 (for animated and color versions, see Supplemental Figures S3 to S8, https://doi.org/10.3168/jds.2018-15480) as well as Table 2. In total, 10 genome-wide significant associa- tions were detected involving 4 traits or combinations of traits and 3 SNP markers located on 3 chromosomes. No genome-wide significant hits were found in the univariate analysis of DMI (Figure 6b, Table 2), which is consistent with previous results (Tetens et al., 2014). From Figures 6 and 7, it becomes obvious that trait associations are clearly lactation stage specific, with a peak at a particular DIM; only some markers show associations over a larger lactation interval (e.g., the association signal for EB on BTA16; see Figure 6a). These results are in line with the reported genetic correlations among lactation stages and emphasize the varying genomic architecture of energy metabolism across lactation, which has to be considered when incorporating this trait complex into a breeding goal. Most of the association results can be ascribed to only a few genomic regions that exhibit effects on different traits. Table 2 summarizes these regions, including all markers associated at a relaxed $P$-value threshold of $P$ $\leq 10^{-5}$, and shows their respective effects. Within this table, each association was assigned to a putative QTL according to the position of the SNP marker and the DIM (e.g., 2 signals were considered as belonging to the same QTL if they are located in the same chromosomal region and exhibit their effect within the same lactation stage). Based on this definition, 6 QTL were identified in the univariate analyses, 3 of which were also found

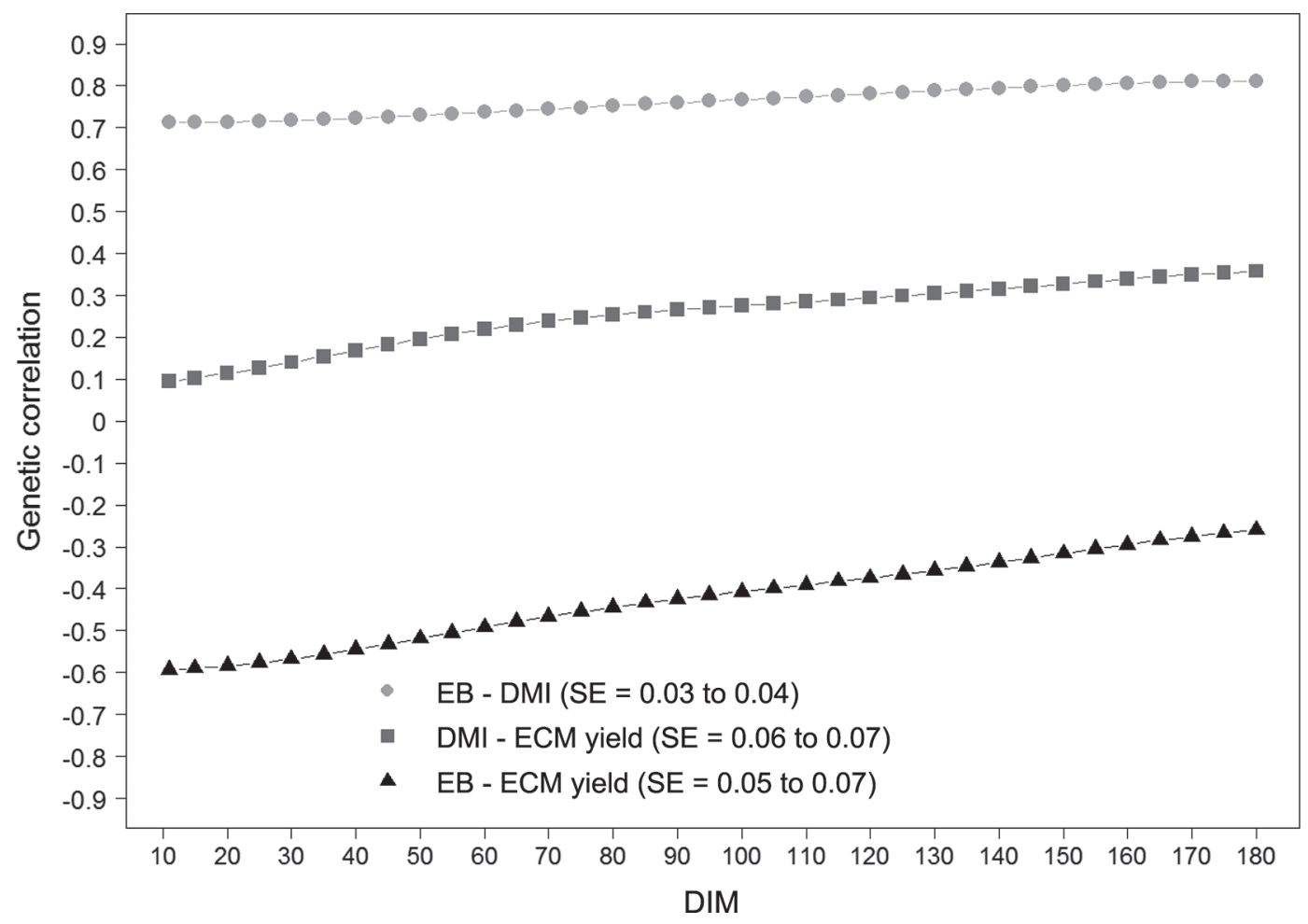

Figure 5. Genetic correlations between energy balance (EB), DMI, and ECM with approximate SE in parentheses across the first 180 DIM estimated from random regression models. 
in bi- and multivariate runs. Six additional QTL were detected only in bi- and multivariate analyses.

Two QTL, namely numbers 4 and 9, were consistently mapped across more than 2 different GWA runs (Table 2 ). The QTL 4 is located around $36 \mathrm{Mbp}$ on BTA16 and exhibits effects toward the end of the analyzed lactation period. In the univariate analysis, a negative effect on EB was estimated and was consistently found in the bivariate analyses involving EB as well. The signs of the effect estimates for DMI and ECM in these analyses are negative and positive, respectively, which is in accordance with the results from the bivariate analysis involving these latter 2 traits. Generally, a QTL influencing EB can act on energy input (i.e., basically DMI), energy output (i.e., basically ECM), or energy allocation (e.g., reflected by body fat mobilization or deposition; Puillet et al., 2016). The latter could be evaluated only by considering weight change as a trait, which was, however, not done here. The QTL 4 most likely affects EB by exhibiting adverse effects on ECM and DMI. The simultaneous analysis of EB and its key determinants DMI and ECM thus provides

\section{a) EB}

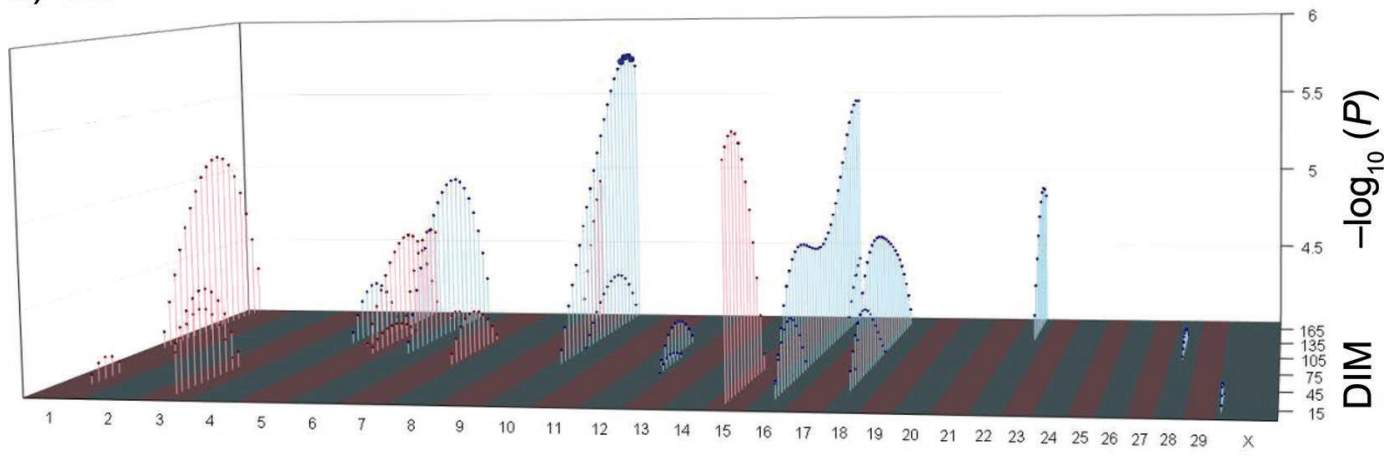

b) DMI

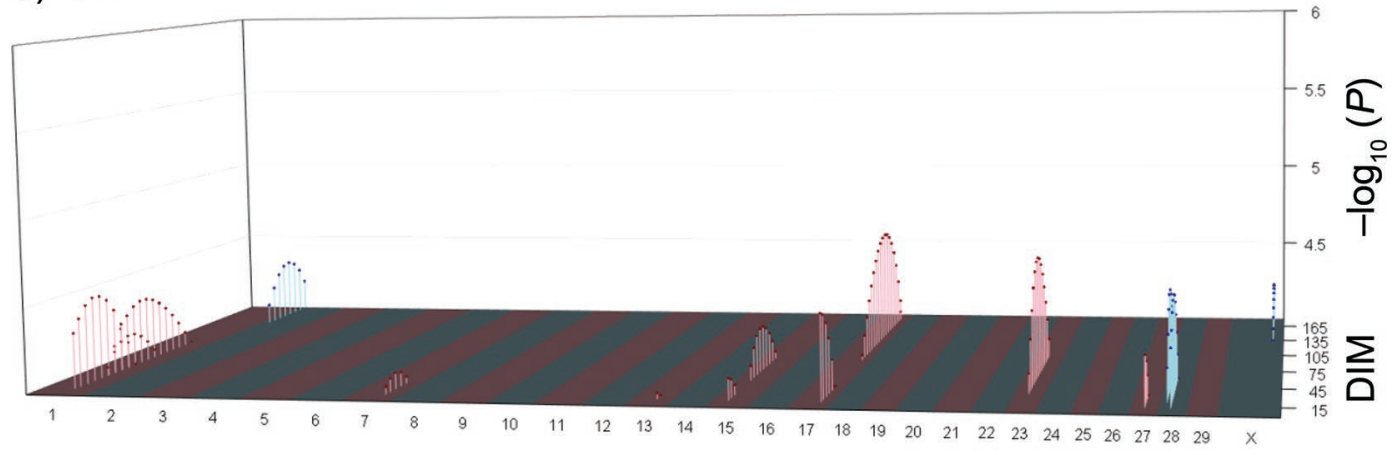

c) $\mathrm{ECM}$

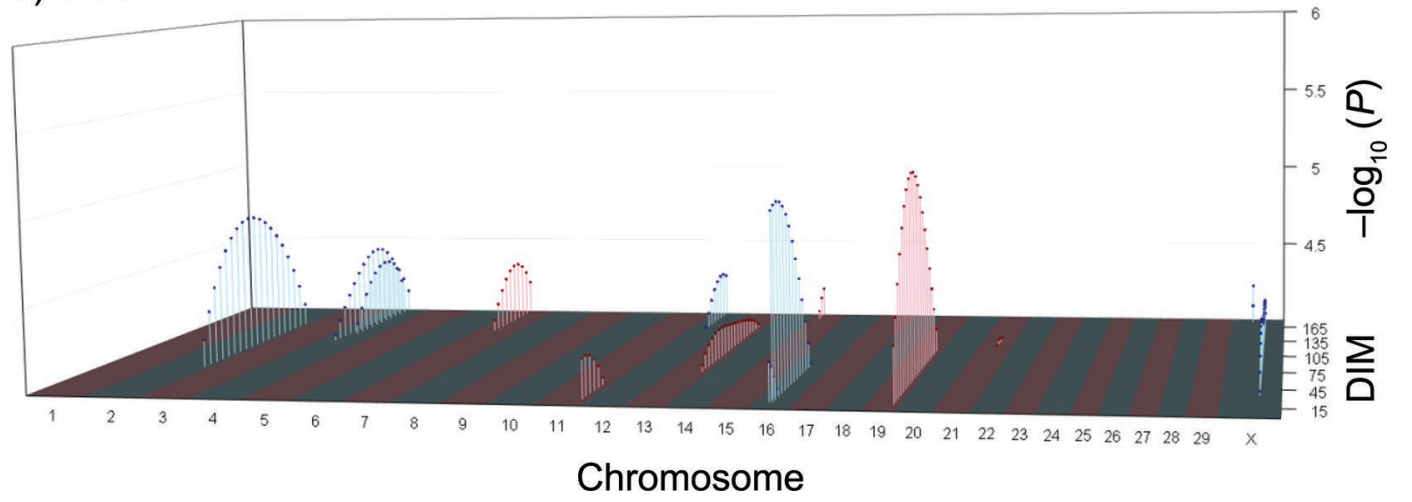

Figure 6. Three-dimensional Manhattan plots depicting the results of univariate genome-wide association analyses. The x- and $\mathrm{y}$-axes represent genomic coordinate (UMD 3.1; https://oct2018.archive.ensembl.org/Bos_taurus/Info/Annotation) and negative decadic logarithm of the $P$-value, respectively. The z-axis represents lactation day. Only results with $-\log _{10}(P) \geq 4$ are shown; larger dots indicate genome-wide significant associations. EB = energy balance. For a better visualization, animated versions of the plots can be found in Supplemental Figures S3 to S5 (https://doi.org/10.3168/jds.2018-15480). 


\section{a) EB-DMI (bivariate)}

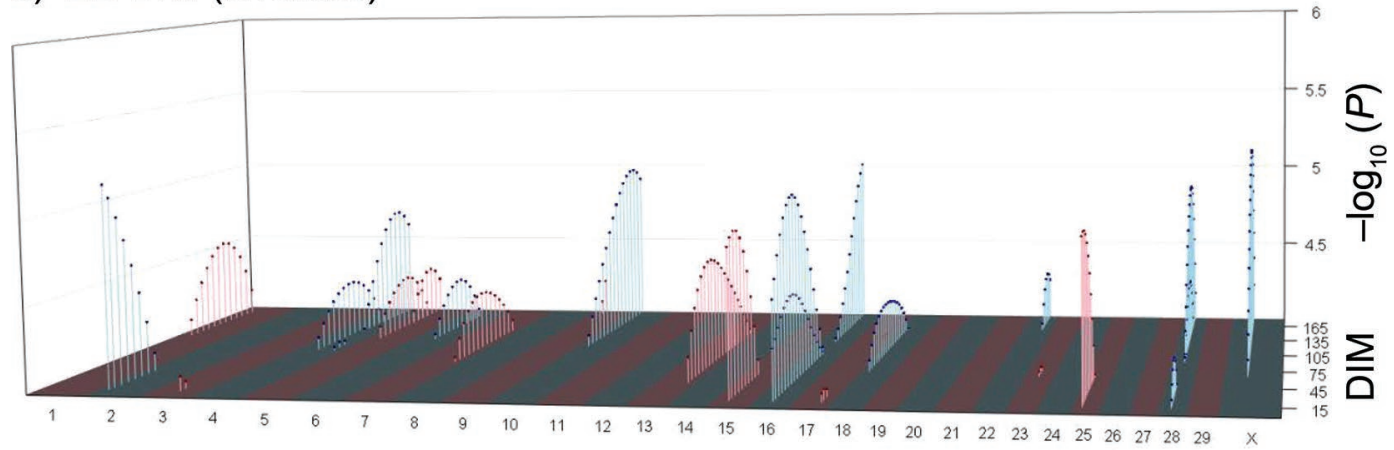

b) EB-ECM (bivariate)

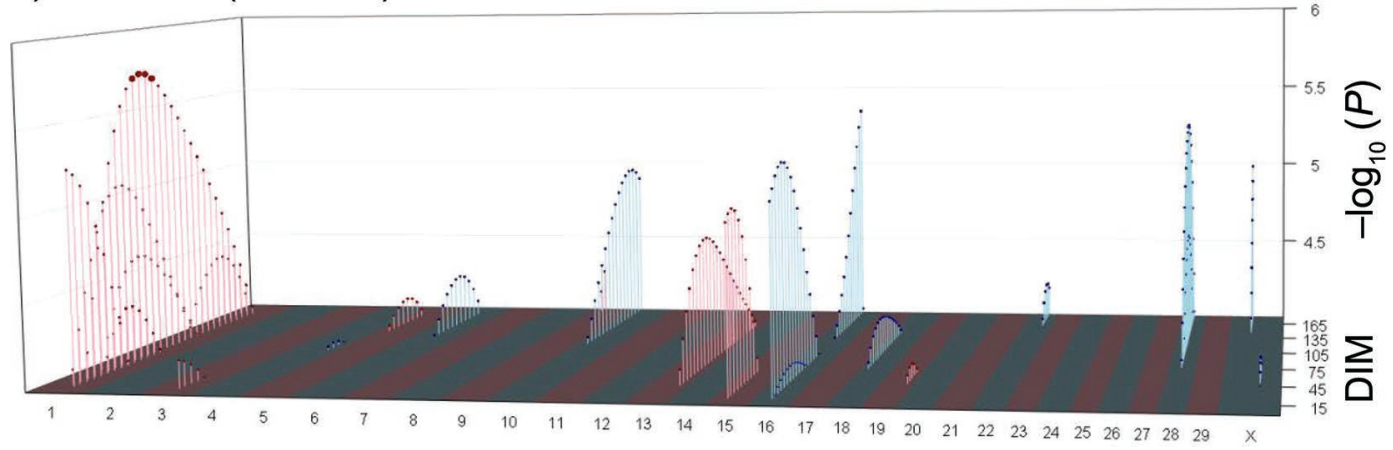

c) DMI-ECM (bivariate)

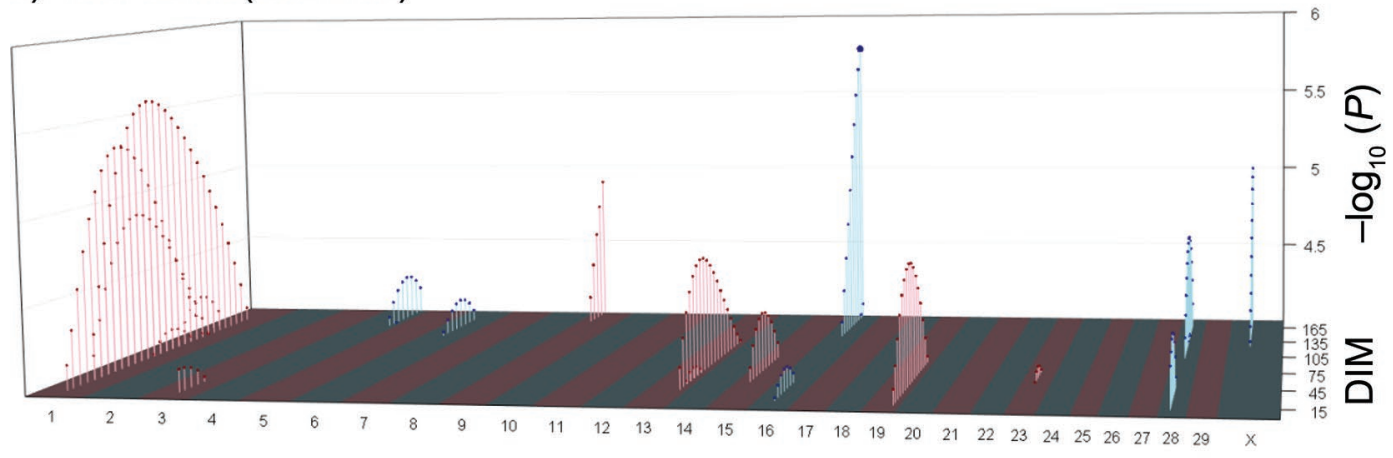

d) EB-DMI-ECM (multivariate)

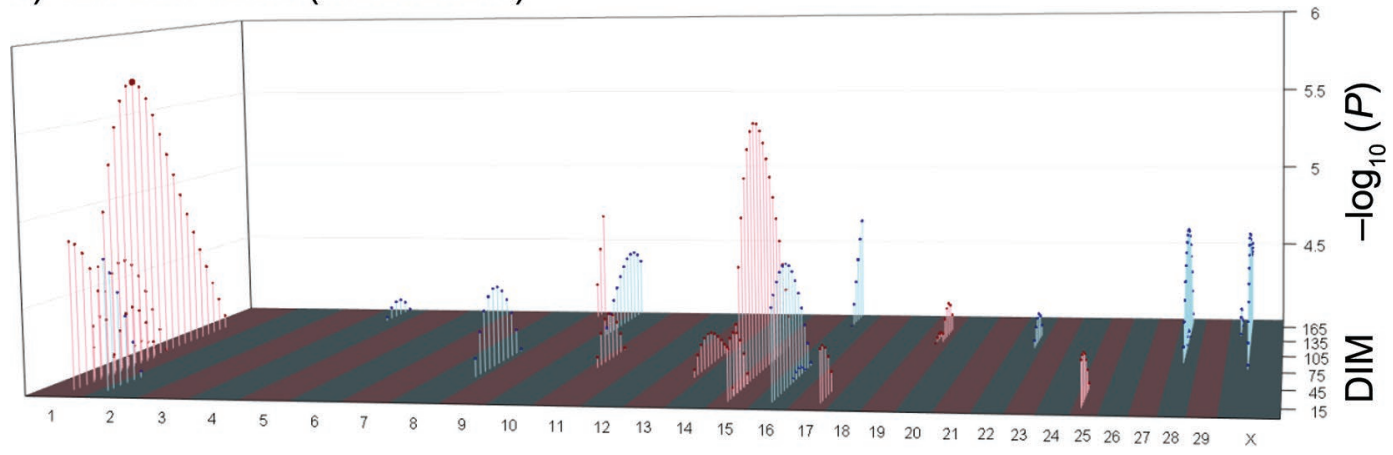

\section{Chromosome}

Figure 7. Three-dimensional Manhattan plots depicting the results of bi- and multivariate genome-wide association analyses. The $\mathrm{x}-$ and y-axes represent genomic coordinate (UMD 3.1; https://oct2018.archive.ensembl.org/Bos_taurus/Info/Annotation) and negative decadic logarithm of the $P$-value, respectively. The z-axis represents lactation day. Only results with $-\log _{10}(P) \geq 4$ are shown; larger dots indicate genomewide significant associations. $\mathrm{EB}=$ energy balance. For a better visualization, animated versions of the plots can be found in Supplemental Figures S6 to S8 (https://doi.org/10.3168/jds.2018-15480). 


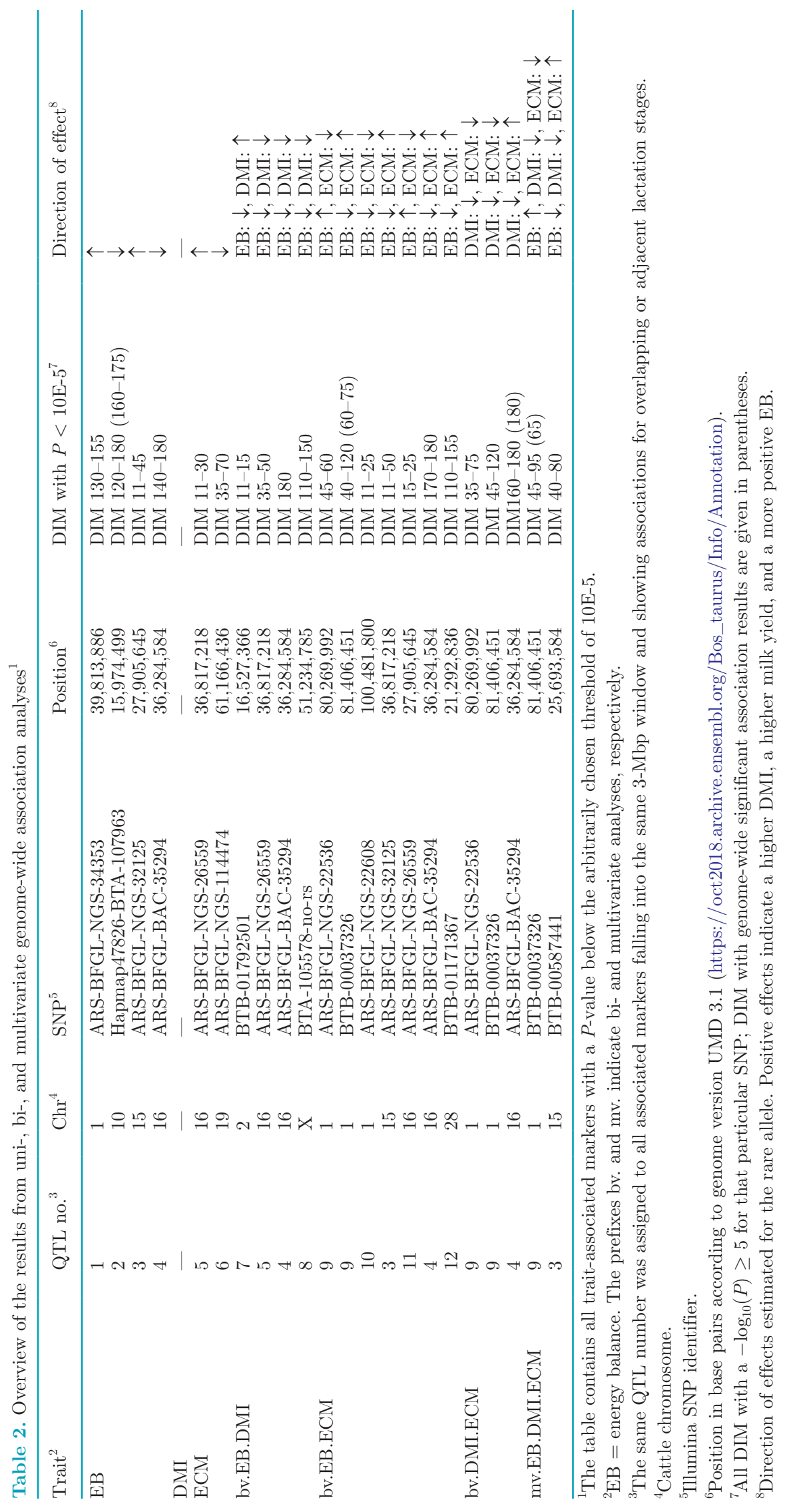


mechanistic insights with respect to possible underlying genes. Screening the QTL region on BTA16 for possible candidate genes revealed the gene encoding fumarate hydratase to be located only $200 \mathrm{~kb}$ apart from the best associated SNP. This enzyme, also termed fumarase, belongs to the Krebs cycle, which could be viewed as the "turntable" of energy metabolism. From this point of view, it might be a promising candidate gene. In humans, genetic variation in this has been mainly reported to be involved in the development and progression of cancer (Sajnani et al., 2017) as well as severe fumarase deficiency syndromes (Ryder et al., 2018). The activity of fumarase in the nucleus accumbens has been described as a biomarker for addiction and eating disorders in humans (Alguacil et al., 2011). It has also been related to palatable food seeking in mice (PérezOrtiz et al., 2017), and upregulation in the brain has been observed as a consequence of food deprivation in rats (Lizárraga-Mollinedo et al., 2013).

The QTL 9 is located on BTA1 between 80 and 82 Mbp and consistently shows up as associated around DIM 65 in the bivariate analyses for EB and ECM and for DMI and ECM as well as in the multivariate analysis incorporating all 3 traits, but not in univariate analyses. As for QTL 4, the estimated SNP effects for EB and ECM (Table 2) have different signs, whereas those for DMI and ECM have the same sign. The effect estimate for ECM is, however, roughly 2.5 times larger than that for DMI, which explains the effect on EB. We also screened the respective genome regions for candidate genes and found the adiponectin-encoding gene $A D I P O Q$ to be located only approximately $400 \mathrm{kbp}$ apart from the best associated marker BTB-00037326. Adiponectin, which is secreted by adipocytes, exerts insulin-sensitizing effects, and in obesity-linked insulin resistance it has been shown to be downregulated along with its receptors (Caselli, 2014). In dairy cows, positive associations between serum adiponectin levels and insulin responsiveness of the glucose and fatty acid metabolism have been established, whereas a negative association has been reported with BCS during the dry period (De Koster et al., 2017). Other studies reported the negative influence of high NEFA levels on feed intake, where adiponectin also plays a regulatory role (Kuhla et al., 2016). Interestingly, a variable duplication in the $A D I P O Q$ promoter was reported to be associated with marbling, rib-eye area, and fat thickness in beef cattle (Zhang et al., 2014).

\section{CONCLUSIONS}

Based on longitudinal and multivariate analyses of EB, DMI, and ECM across the first 180 DIM, we were able to demonstrate a clearly lactation stage-specific genetic architecture of energy homeostasis with heritability estimates and genetic correlations that varied in the course of lactation and DIM- or lactation stagedependent association signals. It seems possible to optimize the lactation trajectory of especially DMI to improve animal health in early lactation and efficiency in later lactation. Based on GWAS results, we identified the genes encoding fumarate hydratase and adiponectin as possible candidates. However, studies with larger cohorts, ideally at the sequence level and including additional traits such as weight change or metabolomics data, will have to be conducted in the future to confirm and refine these results.

\section{ACKNOWLEDGMENTS}

The authors gratefully acknowledge financial support from the German Federal Ministry of Education and Research (project FUGATO-plus GENO TRACK, grant no. 0315134A) from the Kompetenzzentrum MilchSchleswig-Holstein (Kiel, Germany) and from the NOG Nord-Ost Genetic GmbH and Co. KG (Verden, Germany). The authors thank Wolfgang Junge (Institute of Animal Breeding and Husbandry, Kiel University, Kiel, Germany) and staff at the Karkendamm research farm (Institute of Animal Breeding and Husbandry, Christian-Albrechts-University, Kiel, Germany) for data collection over a number of years.

\section{REFERENCES}

Alguacil, L. F., E. Salas, and C. González-Martín. 2011. Identification of new drug targets and biomarkers related to obesity and eating disorders: An approach based on reward deficit and addiction. Curr. Pharm. Des. 17:462-470.

Ali, T. E., and L. R. Schaeffer. 1987. Accounting for covariances among test day milk yields in dairy cows. Can. J. Anim. Sci. 67:637-644.

Bauman, D. E., and W. B. Currie. 1980. Partitioning of nutrients during pregnancy and lactation: A review of mechanisms involving homeostasis and homeorhesis. J. Dairy Sci. 63:1514-1529.

Berry, D. P., M. P. Coffey, J. E. Pryce, Y. de Haas, P. Løvendahl, N. Krattenmacher, J. J. Crowley, Z. Wang, D. Spurlock, K. Weigel, K. Macdonald, and R. F. Veerkamp. 2014. International genetic evaluations for feed intake in dairy cattle through the collation of data from multiple sources. J. Dairy Sci. 97:3894-3905.

Berry, D. P., B. Horan, M. O'Donovan, F. Buckley, E. Kennedy, M. McEvoy, and P. Dillon. 2007. Genetics of grass dry matter intake, energy balance, and digestibility in grazing Irish dairy cows. J. Dairy Sci. 90:4835-4845.

Buttchereit, N., E. Stamer, W. Junge, and G. Thaller. 2010. Evaluation of five lactation curve models fitted for fat:protein ratio of milk and daily energy balance. J. Dairy Sci. 93:1702-1712.

Byskov, M. V., A. Fogh, and P. Løvendahl. 2017. Genetic parameters of rumination time and feed efficiency traits in primiparous Holstein cows under research and commercial conditions. J. Dairy Sci. 100:9635-9642.

Caselli, C. 2014. Role of adiponectin system in insulin resistance. Mol. Genet. Metab. 113:155-160.

de Haas, Y., J. E. Pryce, M. P. L. Calus, E. Wall, D. P. Berry, P. Løvendahl, N. Krattenmacher, F. Miglior, K. Weigel, D. Spurlock, K. A. Macdonald, B. Hulsegge, and R. F. Veerkamp. 2015. Ge- 
nomic prediction of dry matter intake in dairy cattle from an international data set consisting of research herds in Europe, North America, and Australasia. J. Dairy Sci. 98:6522-6534.

De Koster, J., C. Urh, M. Hostens, W. van den Broeck, H. Sauerwein, and G. Opsomer. 2017. Relationship between serum adiponectin concentration, body condition score, and peripheral tissue insulin response of dairy cows during the dry period. Domest. Anim. Endocrinol. 59:100-104.

Fischer, T. M., A. R. Gilmour, and J. H. J. van der Werf. 2004. Computing approximate standard errors for genetic parameters derived from random regression models fitted by average information REML. Genet. Sel. Evol. 36:363-369.

Gao, X., L. C. Becker, D. M. Becker, J. D. Starmer, and M. A. Province. 2010. Avoiding the high Bonferroni penalty in genome-wide association studies. Genet. Epidemiol. 34:100-105.

Gao, X., J. Starmer, and E. R. Martin. 2008. A multiple testing correction method for genetic association studies using correlated single nucleotide polymorphisms. Genet. Epidemiol. 32:361-369.

Gilmour, A. R., B. J. Gogel, B. R. Cullis, and R. Thompson. 2009. ASReml User Guide. Release 3.0. VSN International, Hemel Hempstead, UK.

Hüttmann, H., E. Stamer, W. Junge, G. Thaller, and E. Kalm. 2009. Analysis of feed intake and energy balance of high-yielding first lactating Holstein cows with fixed and random regression models. Animal 3:181-188.

Karacaören, B., F. Jaffrézic, and H. N. Kadarmideen. 2006. Genetic parameters for functional traits in dairy cattle from daily random regression models. J. Dairy Sci. 89:791-798.

Kirchgeßner, M. 1997. Tierernährung. 10th ed. DLG-Verlag, Frankfurt, Germany.

Kuhla, B., C. C. Metges, and H. M. Hammon. 2016. Endogenous and dietary lipids influencing feed intake and energy metabolism of periparturient dairy cows. Domest. Anim. Endocrinol. 56:S2-S10.

Li, B., W. F. Fikse, J. Lassen, M. H. Lidauer, P. Lovendahl, P. Mantysaari, and B. Berglund. 2016. Genetic parameters for dry matter intake in primiparous Holstein, Nordic Red, and Jersey cows in the first half of lactation. J. Dairy Sci. 99:7232-7239.

Li, B., W. F. Fikse, P. Løvendahl, J. Lassen, M. H. Lidauer, P. Mäntysaari, and B. Berglund. 2018. Genetic heterogeneity of feed intake, energy-corrected milk, and body weight across lactation in primiparous Holstein, Nordic Red, and Jersey cows. J. Dairy Sci. 101:10011-10021.

Liinamo, A.-E., P. Mäntysaari, and E. A. Mäntysaari. 2012. Short communication: Genetic parameters for feed intake, production, and extent of negative energy balance in Nordic Red dairy cattle. J. Dairy Sci. 95:6788-6794.

Lizárraga-Mollinedo, E., C. Álvarez, E. Fernández-Millán, F. Escrivá, C. González-Martín, E. Salas, J. M. Pérez-Ortiz, and L. F. Alguacil. 2013. Undernutrition upregulates fumarate hydratase in the rat nucleus accumbens. Metab. Brain Dis. 28:111-115.

Manzanilla Pech, C. I. V., R. F. Veerkamp, M. P. L. Calus, R. Zom, A. van Knegsel, J. E. Pryce, and Y. de Haas. 2014. Genetic parameters across lactation for feed intake, fat- and protein-corrected milk, and liveweight in first-parity Holstein cattle. J. Dairy Sci. 97:5851-5862.

Pérez-Ortiz, J. M., A. Galiana-Simal, E. Salas, C. González-Martín, M. García-Rojo, and L. F. Alguacil. 2017. A high-fat diet combined with food deprivation increases food seeking and the expression of candidate biomarkers of addiction. Addict. Biol. 22:1002-1009.

Pryce, J. E., J. Johnston, B. J. Hayes, G. Sahana, K. A. Weigel, S. McParland, D. Spurlock, N. Krattenmacher, R. J. Spelman, E.
Wall, and M. P. L. Calus. 2014. Imputation of genotypes from low density (50,000 markers) to high density (700,000 markers) of cows from research herds in Europe, North America, and Australasia using 2 reference populations. J. Dairy Sci. 97:1799-1811.

Puillet, L., D. Réale, and N. C. Friggens. 2016. Disentangling the relative roles of resource acquisition and allocation on animal feed efficiency: Insights from a dairy cow model. Genet. Sel. Evol. 48:72.

Purcell, S., B. Neale, K. Todd-Brown, L. Thomas, M. A. Ferreira, D. Bender, J. Maller, P. Sklar, P. I. de Bakker, M. J. Daly, and P. C. Sham. 2007. PLINK: A tool set for whole-genome association and population-based linkage analyses. Am. J. Hum. Genet. $81: 559-575$.

Rauw, W. M., E. Kanis, E. N. Noordhuizen-Stassen, and F. J. Grommers. 1998. Undesirable side effects of selection for high production efficiency in farm animals: A review. Livest. Prod. Sci. 56:15-33.

Ryder, B., F. Moore, A. Mitchell, S. Thompson, J. Christodoulou, and S. Balasubramaniam. 2018. Fumarase deficiency: A safe and potentially disease modifying effect of high fat/low carbohydrate diet. JIMD Rep. 40:77-83.

Sajnani, K., F. Islam, R. A. Smith, V. Gopalan, and A. K.-Y. Lam. 2017. Genetic alterations in Krebs cycle and its impact on cancer pathogenesis. Biochimie 135:164-172.

Shetty, N., P. Lovendahl, M. S. Lund, and A. J. Buitenhuis. 2017. Prediction and validation of residual feed intake and dry matter intake in Danish lactating dairy cows using mid-infrared spectroscopy of milk. J. Dairy Sci. 100:253-264.

Spurlock, D. M., J. C. M. Dekkers, R. Fernando, D. A. Koltes, and A. Wolc. 2012. Genetic parameters for energy balance, feed efficiency, and related traits in Holstein cattle. J. Dairy Sci. 95:5393-5402.

Strucken, E. M., Y. C. S. M. Laurenson, and G. A. Brockmann. 2015. Go with the flow-Biology and genetics of the lactation cycle. Front. Genet. 6:118.

Tetens, J., G. Thaller, and N. Krattenmacher. 2014. Genetic and genomic dissection of dry matter intake at different lactation stages in primiparous Holstein cows. J. Dairy Sci. 97:520-531.

Veerkamp, R. F., and R. Thompson. 1999. A covariance function for feed intake, live weight, and milk yield estimated using a random regression model. J. Dairy Sci. 82:1565-1573.

von Leesen, R., J. Tetens, E. Stamer, W. Junge, G. Thaller, and N. Krattenmacher. 2014. Effect of genetic merit for energy balance on luteal activity and subsequent reproductive performance in primiparous Holstein-Friesian cows. J. Dairy Sci. 97:1128-1138.

Wallén, S. E., E. Prestløkken, T. H. E. Meuwissen, S. McParland, and D. P. Berry. 2018. Milk mid-infrared spectral data as a tool to predict feed intake in lactating Norwegian Red dairy cows. J. Dairy Sci. 101:6232-6243.

Yang, J., S. H. Lee, M. E. Goddard, and P. M. Visscher. 2011. GCTA: A tool for genome-wide complex trait analysis. Am. J. Hum. Genet. 88:76-82.

Zhang, L., M. Yang, C. Li, Y. Xu, J. Sun, C. Lei, X. Lan, C. Zhang, and $\mathrm{H}$. Chen. 2014. Identification and genetic effect of a variable duplication in the promoter region of the cattle ADIPOQ gene. Anim. Genet. 45:171-179.

Zhou, X., and M. Stephens. 2012. Genome-wide efficient mixed-model analysis for association studies. Nat. Genet. 44:821-824.

Zhou, X., and M. Stephens. 2014. Efficient multivariate linear mixed model algorithms for genome-wide association studies. Nat. Methods 11:407-409. 